\title{
Early verb inflection in Lithuanian
}

\author{
Paweł Wójcik \\ Warsaw \\ pwojcik@mercury.ci.uw.edu.pl
}

\section{Adult oral verb inflection of Lithuanian}

Lithuanian is a highly inflected synthetic language belonging to the Baltic branch of IndoEuropean languages. The only other living language belonging to this group is Latvian ${ }^{1}$. Baltic is closely related to Slavic.

\subsection{The Lithuanian verb system ${ }^{2}$}

The inflectional system of the Lithuanian verb is based on tense/mood distinctions: There are three moods (Indicative, Conditional, Imperative) and three synthetic tenses (Present, Past, Future $\left.^{3}\right)$. Verbs are inflected for three persons and two numbers. Nominal/pronominal reference is optional. There is no number distinction in the $3^{\text {rd }}$ person, and, except for participles, no gender distinction in verbs.

The markers of categories are fusional endings; in some verbs, tense is additionally marked by means of morphophonemic alternations in the stem.

Aspectual distinctions (imperfective vs. perfective and habitual in the Past) are introduced by means of prefixes and suffixes. However, there are no systematic oppositions between perfective and imperfective forms, as there are in the case of the Slavic languages, so that aspect is considered a semi-grammatical category in Lithuanian.

Non-finite categories are represented by the Infinitive and a large set of participles (declinable and indeclinable, marked for tense and voice).

\subsection{Inflection}

In Lithuanian there are three main conjugations in the Present and two conjugations in the Past tense (for examples of inflectional paradigms see Table A1 in the appendix). The Future tense and the marked moods (Imperative, Conditional) are derived from the Infinitive stem. Thus, normally, the three basic forms one has to know in order to construct the whole paradigm are: the Infinitive, the $3^{\text {rd }}$ person Present and the $3^{\text {rd }}$ person Past.

Traditionally, verbs are assigned to a conjugation class according to their stem suffix. This stem suffix is most transparent in the $3^{\text {rd }}$ person forms, which consist of bare stems. In the Present tense, verbs with the stem suffix $-a$ form the $1^{\text {st }}$ conjugation, verbs with the stem suffix $-i$ - the $2^{\text {nd }}$ conjugation, and verbs with $-o-$ the $3^{\text {rd }}$ conjugation.

The acquisition of Latvian has been studied by Velta Rūḳe-Dravina (see Rūķe-Dravina, 1982 for references).

2 Authors of contemporary grammars of Lithuanian differ in their opinion as to the number of grammatical categories of the verb and to the way of classifying particular categories. Here, an approach similar to that of Paulauskienè, 1979 is taken. For a more detailed description of the Lithuanian verb system see Ambrazas e.a., 1997.

3 Most of Lithuanian grammars include into the system of tenses the fourth synthetic tense - Past Frequentative (based on the Infinitive stem and denoting habituality). The category did not occur in the data studied. 
In the two conjugations of the Past tense, verbs with the stem suffix -0 (as in the $3^{\text {rd }}$ conjugation in the Present tense) form the first (A) conjugation, and verbs with the stem suffix $-\dot{e}$ - the second (B) conjugation. Verbs belonging to the $1^{\text {st }}$ or the the $3^{\text {rd }}$ conjugation in the Present may belong to either conjugation, $\mathrm{A}$ or $\mathrm{B}$, in the Past. All verbs belonging to the $2^{\text {nd }}$ conjugation in the Present have the stem suffix $-o$ in the Past.

One can thus distinguish five major conjugational classes in Lithuanian (cf. Wójcik and Smoczyńska, 1997): 1A, e.g. supti, supa, supo 'swing'; 1B, e.g. kelti, kelia, kèle 'lift, pick up'; 2A, e.g. turèti, turi, turèjo '1. have, 2. must'; 3A, e.g. žinoti, žino, žinojo 'know'; 3B, e.g. daryti, daro, dare '1. do, 2. make'

Verb inflection is, in general, strikingly regular. The endings are superstable markers (cf. Dressler, 1995) - they are the same across all synthetic tenses and in the Imperative plural: 1sg $--u, 2 \mathrm{sg}-i ; 1 \mathrm{pl}-m(e) ; 2 \mathrm{pl}-t(e)$.

In some verbs belonging to the $2^{\text {nd }}$ conjugation (mylet $i$ 'love'), the forms of the $2 \mathrm{sg}$ and the $3^{\text {rd }}$ person are homophonous in the Present tense. In others (e.g. turéti) - the $2 \mathrm{sg}$ and $3^{\text {rd }}$ person forms are differentiated by stress.

\subsection{Verb structure}

According to their stem structure, Lithuanian verbs are divided into three classes: (i) primary verbs with the structural pattern root-ending ${ }^{4}$ in all basic forms (sup- $t i$; sup- $a$, sup-o); they may belong to conjugation $1 \mathrm{~A}$ or $1 \mathrm{~B}$; (ii) secondary verbs with the structure root + suffixending (aug+in-ti, aug+in-a, aug+in-o 'to grow sb. or sth.'); these belong to conjugation 1A; and (iii) mixed type verbs (dar+y-ti, dar-o,dar-é; žin $+o-t i, z \check{z} i n-o, z ̌ i n+o j-o$ ) which may belong to conjugation $2 \mathrm{~A}, 3 \mathrm{~A}$ or $3 \mathrm{~B}$.

Morphophonemic modifications in primary verbs (consonant infixes and suffixes, quantitative alternations, qualitative gradations) are quite frequent.

As mentioned above, prefixation is one of the devices used to mark aspectual distinctions in Lithuanian. Moreover, prefixes often convey spatial relations (e.g. deti - 'put': pa-dèti - 'put down'; $s u$-deti - 'put together'; $\dot{k}$-deti - 'put into'); sometimes they also modify lexical meaning (e.g. pa-dèti - 'help').

Verbs are negated by means of the prefix ne- (also nebe- 'no more'). Reflexivity is marked with a mobile affix $s(i)$ which takes final position in simplex verbs and moves to the position directly before the root when a verb is prefixed or/and negated, e.g. supa-si 'is swinging', nesi-supa 'is not swinging'.

In the case of reflexive forms, the use of a prefix influences the inflection. When reflexive verbs are not prefixed (i.e. when the reflexive affix is at the end of the word), the $1 \mathrm{sg}$ and $2 \mathrm{sg}$ markers of the $1^{\text {st }}$ and $2^{\text {nd }}$ conjugation of the Present tense, as well as the $1 \mathrm{sg}$ and 2 sg markers of the Future tense, change from $-u$ and $-i$ to $-u o-$ and $-i e$ - respectively: Pres. $1 \mathrm{sg} s u p-u-\mathrm{rfl}$. sup-uo-si, Fut.1sg sup-s-iu: rfl. sup-s-iuo-s. In the plural of all moods and conjugations the markers have the long vowel $\dot{e}$ : Pres.1sg sup $+a-m(e)-\operatorname{rfl}$. sup $+a-m \dot{e}-s$.

4 Or stem suffix in the $3^{\text {rd }}$ person. 


\section{The database}

\subsection{General data description}

The source of the data used in this paper are recordings of conversations with a Lithuanian girl, Rūta. Rūta lives in Vilnius and is the only child in the family. Both parents speak standard Lithuanian without dialectal influences. The recordings were taken on a free basis without a fixed schedule, then transcribed by the mother of the child, double-checked and coded in accordance with CHILDES by the author of the paper. At the moment of writing this contribution the data taken between 1;7-2;5 have been fully processed. Over this period about 34.5 hours of recordings were collected.

Table 1. Rüta's data processed

\begin{tabular}{|c|c|c|c|}
\hline AGE & DURATION & $\begin{array}{c}\text { PRODUCTIONS } \\
\text { (Rüta / input) }\end{array}$ & $\begin{array}{c}\text { VERB TOKENS } \\
\text { (Rüta / input) }\end{array}$ \\
\hline $1 ; 7$ & $35 \mathrm{~min}$. & $293 / 383$ & $42 / 304$ \\
\hline $1 ; 8$ & 1h $5 \mathrm{~min}$. & $1018 / 1448$ & $119 / 1156$ \\
\hline $1 ; 9$ & $3 \mathrm{~h} 45 \mathrm{~min}$ & $2635 / 3120$ & $416 / 2504$ \\
\hline $1 ; 10$ & 4h 15 min. & $2735 / 2978$ & $897 / 2603$ \\
\hline $1 ; 11$ & $2 \mathrm{~h} 40 \mathrm{~min}$. & $1590 / 1466$ & $925 / 1196$ \\
\hline $2 ; 0$ & $3 \mathrm{~h} 15 \mathrm{~min}$. & $1796 / 2008$ & $871 / 1553$ \\
\hline $2 ; 1$ & $3 \mathrm{~h} 20 \mathrm{~min}$. & $1776 / 1410$ & $1291 / 1348$ \\
\hline $2 ; 2$ & $3 \mathrm{~h} 45 \mathrm{~min}$. & $1861 / 1644$ & $1355 / 1633$ \\
\hline $2 ; 3$ & $3 \mathrm{~h} 45 \mathrm{~min}$. & $2011 / 1789$ & $1372 / 1716$ \\
\hline $2 ; 4$ & $3 \mathrm{~h} 35 \mathrm{~min}$. & $2065 / 1467$ & $1303 / 1292$ \\
\hline $2 ; 5$ & $3 \mathrm{~h} 10 \mathrm{~min}$. & $1809 / 1469$ & $1074 / 1428$ \\
\hline TOTAL & $34 h 20 \mathrm{~min}$ & $19589 / 19182$ & $9665 / 16733$ \\
\hline
\end{tabular}

\subsection{Data portion analysed for this contribution}

The data portion studied in this paper covers the period from $1 ; 7$ till 1;10 when Rüta begins the protomorphological stage of linguistic development. Over that period about 9.5 hours of recordings were taken during which the girl produced 6491 utterances 5 .

The numbers in the third column of Table 2. show the number of days in the course of which the recordings were taken. It can easily be seen that both the duration of the data portions and the number of sessions differed for particular months. This fact should be borne in mind especially when analysing the results of calculations given in absolute numbers.

Table 2. Rūta's data used in the paper.

\begin{tabular}{|c|c|c|r|}
\hline AGE & DURATION & $\begin{array}{c}\text { No. of } \\
\text { SESSIONS }\end{array}$ & UTTERANCES \\
\hline \hline $\mathbf{1 ; 7}$ & $35 \mathrm{~min}$. & $\mathbf{5}$ & 283 \\
\hline $\mathbf{1 ; 8}$ & hh $5 \mathrm{~min}$. & 15 & 959 \\
\hline $\mathbf{1 ; 9}$ & 3h $45 \mathrm{~min}$ & 19 & 2576 \\
\hline $\mathbf{1 ; 1 0}$ & $4 \mathrm{~h} 15 \mathrm{~min}$. & 24 & 2673 \\
\hline TOTAL & $\mathbf{9 h ~ 4 0 ~} \mathbf{m i n}$ & $\mathbf{7 3}$ & $\mathbf{6 4 9 1}$ \\
\hline
\end{tabular}

5 Utterance - a production with at least one identifiable unit. 


\subsection{Verbs singled out for the analysis}

Two different kinds of methodological approaches in selecting verbs for analysis were adopted in this paper. In the sections 3-4 and 6, where the process of verb acquisition in general is discussed, we excluded from the analysis: (i) amorphous baby talk forms, onomatopoeia etc., (ii) verbs which could not be clearly identified even if their form and/or syntactic position attested that they might be predicates, and (iii) citations, nursery rhymes, songs etc. Verb forms which occurred in directly preceding utterances of adults (e.g. forms used in answer to yes/no questions, also non-reversals) are not excluded. It seems impossible to judge in advance which of them might have been imitated and which were creative uses. In the section on the emergence of paradigms (5.0.) a few additional restrictions are made.

\section{The emergence of verb categories in $\mathbf{R u}^{\mathrm{ta}}{ }^{6}$}

At the age of 1;7 the only categories recorded in the girl's speech were Present tense and Imperative $2 \mathrm{sg}$ (see table A1 in the appendix). In the following month Ruta started using infinitives. At 1;9 Past and Future tense as well as the first participles emerged. At this time a verb spurt could be observed. Conditionals were first recorded at 1;10; however, they were used very rarely and almost exclusively in the form of $3^{\text {rd }}$ person.

As far as the category of person is concerned, $3^{\text {rd }}$ person and $1 \mathrm{sg}$ forms could be found in the first portion of the data studied. $2 \mathrm{sg}$ forms were recorded at $1 ; 8$ but all of them were nonreversals occurring in answers to yes/no questions. The first correct instance of $2 \mathrm{sg}$ was found at $1 ; 10$ but it should be emphasised that only at $2 ; 1$ the ratio of non-reversals decreased significantly (from $67 \%$ at $2 ; 0$ to $3 \%$ at $2 ; 1$ ). A 1 pl form was used already at 1;8 (in a hortative expression) and the number of $1 \mathrm{pl}$ increased in the course of the following months. $2 \mathrm{pl}$ verbs were rare in the whole corpus.

Most frequent were $3^{\text {rd }}$ person verbs which were commonly used in self-reference and in addressing the interlocutor. As shown in Table 3, most of the $3^{\text {rd }}$ person forms referred to nonplural subjects. The conversations were child-oriented, so $1 \mathrm{sg}$ forms were more numerous in the girl's utterances than $2 \mathrm{sg}$ forms.

Table 3. The number of the $3^{\text {rd }}$ person forms used in singular and plural contexts in Rūta's utterances.

\begin{tabular}{|l|r|r|r|r|r|r|r|r|r|r|r|r|r|}
\hline & $\mathbf{1 ; 7}$ & $\mathbf{1 ; 8}$ & $\mathbf{1 ; 9}$ & $\mathbf{1 ; 1 0}$ & $\mathbf{1 ; 1 1}$ & $\mathbf{2 ; 0}$ & $\mathbf{2 ; 1}$ & $\mathbf{2 ; 2}$ & $\mathbf{2 ; 3}$ & $\mathbf{2 ; 4}$ & $\mathbf{2 ; 5}$ & TOTAL & $(\%)$ \\
\hline 3sg & 21 & 63 & 198 & 439 & 503 & 437 & 535 & 533 & 567 & 502 & 395 & 4193 & $\mathbf{9 4 , 5}$ \\
\hline 3pl & 0 & 6 & 10 & 1 & 12 & 17 & 34 & 66 & 43 & 28 & 27 & 244 & $\mathbf{5 , 5}$ \\
\hline total & 21 & 69 & 208 & 440 & 515 & 454 & 569 & 599 & 610 & 530 & 422 & 4437 & $\mathbf{4 4 3 7}$ \\
\hline
\end{tabular}

\section{Development of the verbal lexicon}

\subsection{Predecessors of verbs}

In the first months of the data one can find a number of onomatopoeias and words belonging to the common Lithuanian baby-talk lexicon $(\mathrm{BT})^{7}$ used in predicative function, e.g.: $b \bar{u}$ ' go (by a vehicle)', puški-puški 'BT - wash, have a bath'; popa 'BT - hurts', tepu-tepu 'BT walk'; babak! 'BT fall'. Moreover, Rūta used a large number of other BT words and onomatopoeias

6 For a more detailed analysis see Wójcik, 1998, Wójcik in press.

See also Wójcik, 1994. 
whose function is not clear (they might also be used in nominal function), e.g. kar-kar 'BT 1. to fly; 2. a bird', niam-niam 'BT 1. eat; 2. food'; au-au '1. bark; 2. dog'; miau-miau '1. meow; 2. cat' etc.

BT verbs and onomatopoeias were still present in Rūta's speech at 2;5, e.g. padarysiu pyp 'lit. I will do beep' when about to press a computer's button.

\subsection{Verb production}

When studying the development of the lexicon and the problems connected with the emergence of inflection in Lithuanian, one has to be aware of the role of prefixation. In Lithuanian, as mentioned above, prefixes modify the lexical and/or aspectual meaning of verbs. For a long time, however, Rūta tended to omit them or replace them with fillers (Section 6.1). Therefore, when the situation is not completely clear, it is often difficult or even impossible to establish beyond doubt what the verb the child wanted to use exactly was.

What is even more important, in the data studied prefixation did not affect inflection - the non-prefixed reflexive forms referred to in Section 1.3. were very rare in the parents' speech and practically did not occur in the girl's utterances. Thus, when dealing with the development of the lexicon and the acquisition of paradigms, in addition to the notion of lemma, the term identical root with the same stem formations ${ }^{8}$ (further on abbreviated to ISF and written in CAPITALS) will be used. An ISF is defined as an abstract representation of a group of verbs sharing a common root and differing only by the presence or absence of prefixes and/or the reflexive marker. For instance, the lemmas: mokyti 'teach', mokyti-s 'learn', pa-mokyti 'teach for a certain period of time' represent the ISF 'MOKYTI'.

Table 4. presents the development of Ruta's active vocabulary. The calculations were done cumulatively, i.e. new items were added to those found in the earlier portions of the corpus. It can easily be seen that between 1;7 and 2;5 Rüta's lexicon developed considerably. The relatively most rapid growth of the girl's vocabulary took place till 1;11, but later on the number of new ISF and lemmas increased considerably.

Table 4. The number of ISF's and lemmas in Rūta's utterances.

\begin{tabular}{|l|r|r|r|r|r|r|r|r|r|r|r|}
\hline & $\mathbf{1 ; 7}$ & $\mathbf{1 ; 8}$ & $\mathbf{1 ; 9}$ & $\mathbf{1 ; 1 0}$ & $\mathbf{1 ; 1 1}$ & $\mathbf{2 ; 0}$ & $\mathbf{2 ; 1}$ & $\mathbf{2 ; 2}$ & $\mathbf{2 ; 3}$ & $\mathbf{2 ; 4}$ & $\mathbf{2 ; 5}$ \\
\hline ISF & 8 & 26 & 70 & 116 & 144 & 165 & 188 & 213 & 239 & 254 & 267 \\
\hline LEMMA & 8 & 27 & 91 & 167 & 223 & 275 & 327 & 380 & 440 & 482 & 513 \\
\hline
\end{tabular}

A very important point of time in the development of Rūta's lexicon was the age of 1;9, when an expansion of derivational processes took place - the difference between the number of ISF's and the number of lemmas became conspicuous for the first time. In the following months the difference gradually became more salient. Their ratio is represented in Figure 1., where the results of calculations of the data coming from particular sessions recorded during the four months in question are given'.

\footnotetext{
8 The term was proposed by Wolfgang U. Dressler during the workshop of Pre- and Protomorphology (Berlin, 2000). In Wójcik, in press the term 'lemma' is used in the meaning of ISF, and the term 'lexeme' is used for 'lemma'.

9 For the sake of lucidity only the dates of the first and last sessions are given.
} 
Figure 1. The number of verb ISF's and lemmas in Rūta's utterances.

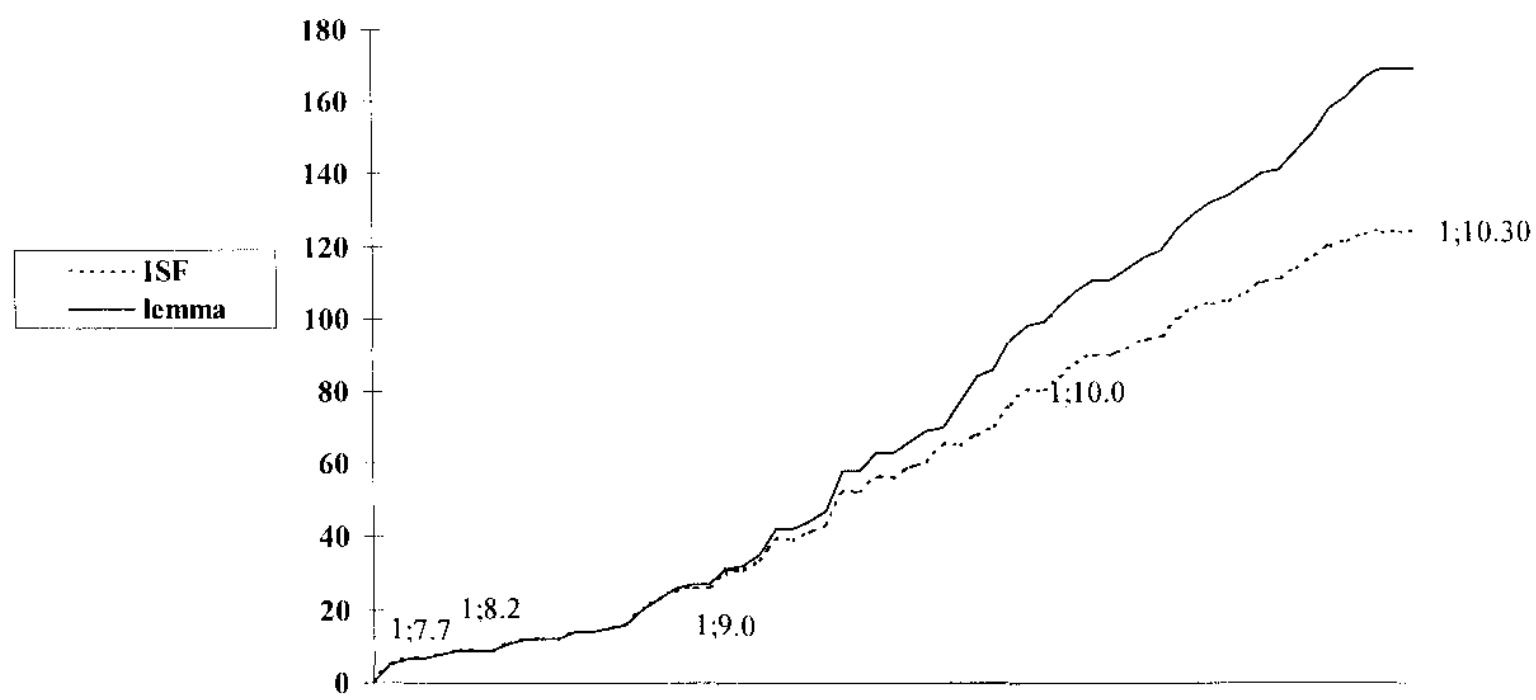

The end of 1;8 and the beginning of 1;9 was the point when a verb spurt could be observed. However, one has to bear in mind that at 1;9 twice the amount of data was collected when compared to the preceding month. On the other hand, the relative frequency of utterances containing a verb (last column of Table 5.) did not change considerably. Only at 1;10 the amount of utterances with verbs reached one-third of all utterances.

Table 5. The development of Rüta's verbal lexicon till the onset of protomorphology ${ }^{10}$

\begin{tabular}{|l|r|r|r|r|r|}
\hline & \multicolumn{1}{|l|}{ ISF } & \multicolumn{1}{l|}{ lemmas } & verb token & utterances & v/utterance \\
\hline \hline $\mathbf{1 ; 7}$ & $8(8)$ & $8(8)$ & 42 & 283 & 14,8 \\
\hline $\mathbf{1 ; 8}$ & $23(26)$ & $24(27)$ & 118 & 959 & 12,3 \\
\hline $\mathbf{1 ; 9}$ & $68(70)$ & $87(91)$ & 419 & 2576 & $\mathbf{1 6 , 2}$ \\
\hline $\mathbf{1 ; 1 0}$ & $97(116)$ & $131(167)$ & 897 & 2673 & 33,5 \\
\hline
\end{tabular}

\section{The development of paradigms}

\subsection{Method}

When studying the emergence of inflectional paradigms we excluded from the analysis ${ }^{11}$ the verb forms occurring in such contexts for which it might be suggested that they were not produced fully spontaneously or that they were modelled in some way on directly preceding adults' utterances. Therefore, the $3^{\text {rd }}$ person verbs used in answers to yes/no questions were excluded, even though such a way of answering questions is a common phenomenon in colloquial Lithuanian. All non-reversals which occurred in analogical contexts were left out of consideration as well. However, the $1 \mathrm{sg}$ forms used in answer to yes/no questions asked in $2 \mathrm{sg}$ were analysed, since their correct use attested that the girl had mastered the category actively.

The assumption was made that if a verb form was used spontaneously at some age, it should be considered acquired when analysing the later portions of the data and recording another form of the same lemma. Thus, when constructing the list of paradigms given below, the search was done cumulatively.

10 The columns 'ISF' and 'lemmas' present the numbers of units in particular months and cumulative results (in brackets).

11 In addition to the instances listed in section 2.3. 


\subsection{Paradigms at 1;7}

ISF 8 , lemmas 8 , verb tokens 42 , utterances - 283

categories - Present: $1 \mathrm{sg}, 3^{\text {rd }}$; Imperative: $2 \mathrm{sg}$

In the first portion of the data collected at this age $(1 ; 7.7)$ no instances of verb forms were recorded. However, during the following sessions the first instance of a two-member paradigm was recorded:

MOKÉTI 1A 'can-dynamic'

7 tokens of (ne)moku Pres.1sg (the first item at 1;7.14) - in answer to a yes/no question containing a Pres.2sg form;

2 tokens of moka Pres. 3 - one fully spontaneous $(1 ; 7.18)$ and one classified as modelled.

Most of other Pres.3 forms were used correctly in answer to yes/no questions. The most frequent verb miega 'sleep:Pres.3' (15 tokens) was used also in answer to wh-questions.

\subsection{Paradigms at $1 ; 8$}

ISF 23 (26); lemmas 24 (27); tokens 118; utterances - 959

categories - Present: $1 \mathrm{sg}, * 2 \mathrm{sg}, 3^{\text {rd }}, 1 \mathrm{pl}$; Future: $* 2 \mathrm{sg}(1$ item $)$; Imperative: $2 \mathrm{sg}$; Infinitive

At 1;8 no instances of mini-paradigms fulfilling the criteria mentioned in 5.0 were found. An unclear instance was MYLÉTI 'love' used erroneously in Pres. 3 form *mylia 'love' in answer to a question asked in 2sg. Another form of the paradigm was myliu Pres. $1 \mathrm{sg}$.

\subsection{Paradigms at $1 ; 9$}

ISF 68 (70); lemmas 87 (91); tokens 419 ; utterances - 2576 categories - Present: $1 \mathrm{sg}, * 2 \mathrm{sg}, 3^{\text {rd }}, 1 \mathrm{pl} ;$ Past: $1 \mathrm{sg}, * 2 \mathrm{sg}, 3^{\text {rd }} ;$ Future: $1 \mathrm{sg}, * 2 \mathrm{sg}, 3^{\text {rd }} ;$ Imperative: $2 \mathrm{sg} ;$ Infinitive As mentioned in Section 4.2.1., at 1;9 a verb spurt was observed. In the same month the first 50 verbs were recorded and the first two-member mini-paradigms appeared. Moreover, two three-member mini-paradigms were recorded, one of them (büti 'be') suppletive.

\subsubsection{Two-member mini-paradigms}

1. KALBÉTI $1 \mathrm{~A}$ 'talk'

1 kalba $[=k a b a]$ Pres. $3 ; 2$ kalbet $i[=k a b e t i]$ Inf.

2. SĖSTI $2 A$ 'sit down'

1 sèsk Imp.2sg; 2 sèst Inf.

3. LAUKTI 1B 'wait'

1 laukiu [=aatiu] Pres.1sg; 2 palauk Imp.2sg;

4. NORETI $2 \mathrm{~A}$ 'want'

1 noriu $[=n o j u]$ Pres. $1 \mathrm{sg} ; 2$ (ne)nori [=nenionia; nenoja $]$ Pres. 3;

5. TUPĖTI $2 \mathrm{~A}$ 'squat'

1 tupiu $[=$ tupu $]$ Pres. $1 \mathrm{sg} ; 2$ tupi $[=$ tipa $]$ Pres. 3

6. ŽIŪRÉTI $2 \mathrm{~A}$ 'watch, look'

1 žiūriu $[=z i \bar{u} j u]$ Pres. $1 \mathrm{sg} ; 2$ žiürèti [=ziüjeti $]$ Inf.;

7. EITI $1 \mathrm{~A}$ 'walk, go'

1 neik neg.Imp.2sg; 2 einam [=eimam] Pres. 1pl (hortative)

\subsubsection{Three-member mini-paradigms}

1. BŪTI $1 \mathrm{~A}$ 'be'

1 yra $[=y j a]$, NEG: nèra $[=n e j a]$ Pres. $3 ; 2$ bus Fut. $3 ; 3$ buvo Past. 3

2. GULÈTI $2 \mathrm{~A}$ 'lie'

1 guliu Pres. 1 sg; 2 guleti Inf.; 3 guli $[=$ gulia $]$ Pres.3; 


\subsection{Paradigms at 1;10}

ISF 97 (116); lemmas 131 (167); tokens 897; utterances - 2673

categories - Present: $1 \mathrm{sg}, * 2 \mathrm{sg}, 3^{\text {rd }}, 1 \mathrm{pl}$; Past: $1 \mathrm{sg}, * 2 \mathrm{sg}, 3^{\text {rd }}, 1 \mathrm{pl}$; Future: $1 \mathrm{sg}, * 2 \mathrm{sg}, 3^{\text {rd }}, 1 \mathrm{pl}$; Conditional: $3^{\text {rd }}$; Imperative: $2 \mathrm{sg}, 1 \mathrm{pl}$; Infinitive

The age of 1;10 was the point of time when the emergence of new mini-paradigms was particularly spectacular. In the data, one can find a very large amount of new two-member mini-paradigms. Moreover, many new forms of the lemmas already recorded in the earlier portions of the data emerged, which accounts for the rise of new three-and-more-member paradigms. For lack of space only the paradigms with at least three different forms are listed below.

\subsubsection{Three-member mini-paradigms}

1. GRIŪTI 1A 'fall'

1 nenugriūsiu $[=$ nekakūsiu $]$ Pres. 1 sg; 2 nugrius $[=a g u s]$ Fut. $3 ; 3$ nugriuvau $[=a g a v a u]$ Past. 3 ;

2. LIPTI 1A 'climb'

1;9: 1 lipa Pres.3;

1;10: 2 lipti $[=$ diti $]$ Inf; 3 lipu Prcs. 1sg;

3. LUPTI IA 'peel'

1;9 1 lири;

1;10 2 lups Fut. $3 ; 3$ nulupau [=alupau $]$ Past. 1 sg

4. MIEGOTI $1 \mathrm{~A}$ 'sleep'

1;7: I miega Pres.3;

1;10: 2 miegos $[=$ megos $]$ Fut. $3 ; 3$ miegot $[=$ magot $]$ Inf.;

5. TEPTI 1B 'smear'

1 patepu $[=$ atepu $]$ Pres. $1 \mathrm{sg} ; 2$ patept $[=$ atep $]$ Inf.; 3 patepk $\operatorname{Imp} .2 \mathrm{sg}$;

6. SĖDĖTI $2 B$ 'sit'

1;9: 1 sédi Pres.3;

1;10: 2 sédżiu $[=s e \dot{d} d u]$ Pres. $1 \mathrm{sg} ; 3$ sèdek [=tedè $]$ Imp.2sg;

7. STATYTI $3 B$ 'build; put on'

1 statom Pres. 1 pl; 2 pastatyk $[=$ patesyk $]$ Imp. 2 sg; 3 pastatysiu $[=$ pastetysiu $]$ Fut. $1 \mathrm{sg}$;

\subsubsection{Larger paradigms}

1. DÉTI 1A 'put'- padeti '1. ts. PF; 2. help'

1 suded $u$ Pres. $1 \mathrm{sg} ; 2$ padès Fut. $3 ; 3$ padessiu Fut. 1sg; 4 padék Imp.2sg;

2. EITI 1A 'walk, go'

1;9: 1 neik; 2 einam;

1;10: 3 eini Pres.2sg; atèjo [=atejo] Past.3; 4 ateis Fut.3; 5 eiti Inf.; 6 eisiu Fut.1sg; 7 eikim [=eikam, eikim] Imp. 2sg;

3. VAŽIUOTI IA 'go (by a vehicle)'

1;9: I važiuos [=teziuos] Fut.3;

1;10: 2 važiuoja [=atioja] Pres. $3 ; 3$ važiuojam [=aziuojam] Pres.1pl; 4. važiuosiu [=vaziuosiu] Fut.1sg; 5 važiuosim $[=$ aziuosim $]$ Fut. I pl;

\section{DUOTI 1B 'give'}

1;7:1 duok;

1;9: 2 duoda;

1;10: 3 duosi Fut.2sg; 4 duosiu Fut. Isg; 5 paduotas (?) Ptc.pf.pass.; 6 neduodu neg:Pres. $1 \mathrm{sg}$;

5. ŽIŪRĖTI 2B 'watch, look'

1;9: 1 żiüriu $[=z i \bar{u} j u]$; 2 : žiüréti $[=z i \overline{u ̈ j e t i}]$;

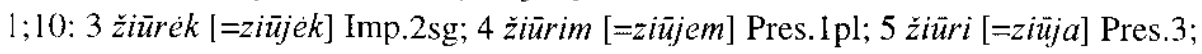

6. DARYTI 3B 'do' padaryti 't.s. PF.', uždaryti 'close', atidaryti 'open'

1 padaryt $[=$ padyt $]$ Inf.; 2 użdaryta $[=$ adedyta $]$ Ptc.pf.pass; 3 daro $[=$ dajo] Past. $3 ; 4$ atidaryk $[=$ atejek $]$ Imp.2sg. 


\section{Morphological substitutions}

\subsection{Fillers}

In the data studied, no instance of a whole verb being replaced with a filler was recorded; the occurrence of fillers instead of prefixes as well as of the reflexive affix in prefixed verbs, however, was quite frequent. Two kinds of fillers were involved in verb production:

(i) a neutral vowel $a$; e.g. Inf. * $a$-det $t i$ for $\dot{l}$-det $t i$ 'put into'; už-deti 'put onto, dress'; pa-déti ' 1 . put; put onto; 2. help' ${ }^{\prime 2}$.

(ii) reduplication: *de-deti for pa-deti.

In the same data portions one can find forms with omitted prefix and with both kinds of fillers alongside correct forms, e.g., at 1;10 the following productions of the perfective verb nukristi 'fall' were recorded (adult form in brackets): (i) correct - Inf. nukist, nukist (nukrist), Past.3 nukito (nukrito); (ii) forms with a-filler - *a-kito (nu-krito or $u z ̌-k r i t o)$; (iii) a form with a reduplicated syllable - *ne-ki-kisiu (ne-nu-krisiu); (iv) a form with omitted prefix - *ne-Økisiu (ne-nu-krisiu).

Reduplicated syllables also replaced the reflexive marker $-s i$ - in prefixed verbs (cf. 1.3): Fut.1sg *a-ma-mausiu for už-si-mausiu 'put on shoes', Past.3*a-ki-kèle for at-si-kèlè 'get up'.

\subsection{Class shifts}

The most conspicuous phenomenon, as far as class shifts are concerned, is that of $2^{\text {nd }}$ conjugation verbs shifting to the $1^{\text {st }}$ conjugation. This could be observed, first of all, in $3^{\text {rd }}$ person forms. The first items of $2^{\text {nd }}$ conjugation verbs were recorded at $1 ; 8$. At this age, almost all $3^{\text {rd }}$ person forms took the stem suffix $-a$ instead of the expected $-i$, e.g. *noj-a for $n o r-i$ 'want'; *séd-a for sed-i 'sit'; *gul-ia for gul-i 'lie'; *tup-a for tup-i 'squat' etc. In the following months the relative frequency of errors decreased gradually and it became insignificant after the age of two. However, in the last portions of the processed data isolated instances of shifts still could be spotted (see Figure 2.). As mentioned above, the shifts could be found not only within the set of the $3^{\text {rd }}$ person forms. Isolated errors such as 1 pl.Pres. *ziujam instead of žiürim 'watch' $(1 ; 11)$ or 1pl.Imp. *mamaukiam instad of užmaukim 'put on shoes' were also recorded.

Other kinds of shifts between conjugational classes were sporadic (limited to 2-3 items which often occurred alongside correct forms in the same portions of the data).

12 The $a$-filler was also used instead of prepositions. 
Figure 2. The proportion of shifts from the $2^{\text {nd }}$ conjugation to the $1^{\text {st }}$ conjugation

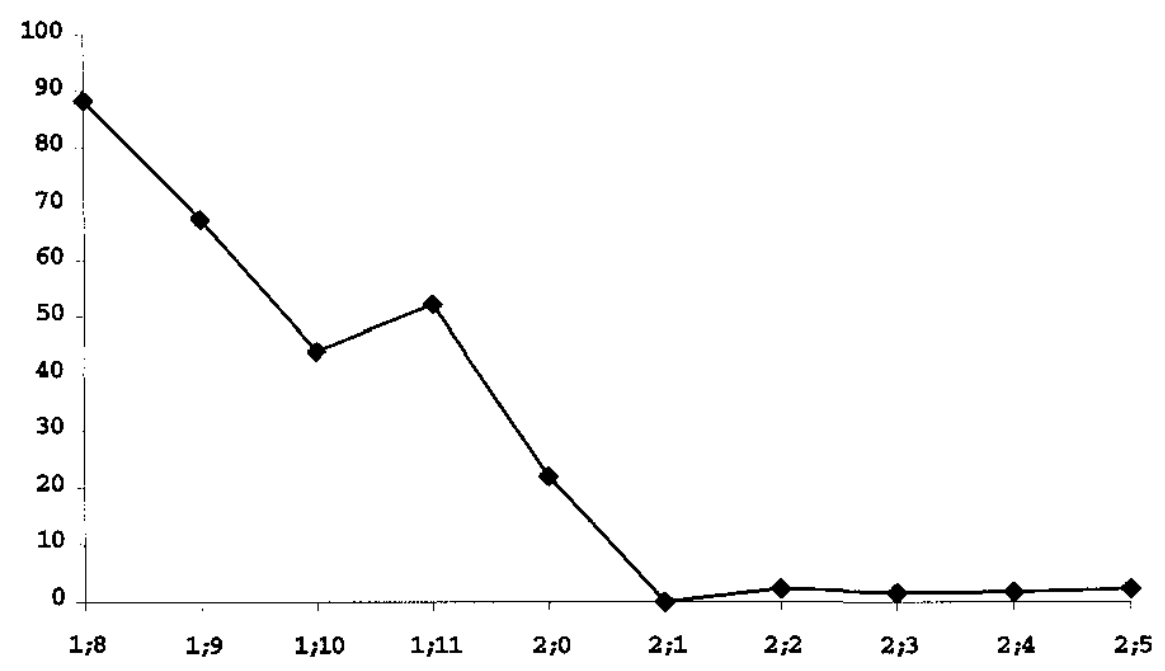

The explanation for the occurrence of such shifts should be sought in two factors ${ }^{13}$ :

First, the $1^{\text {st }}$ conjugation verbs constitute the largest class in Lithuanian. The relative frequency of ISF types in the input and in Rūta's utterances exceeded $70 \% .2^{\text {nd }}$ conjugation ISF types were the least numerous: $7 \%$ in Ruta and $4.5 \%$ in the input, and the relative frequency of the $3^{\text {rd }}$ conjugation IFS was about $18 \%$ in both registers. With regard to token frequency the situation was slightly different, as most modal verbs belong to class $2 \mathrm{~A}$. Thus, the relative frequency of the $1^{\text {st }}$ and $3^{\text {rd }}$ conjugation ISF tokens was smaller than the frequency of ISF types. The ratio of $2^{\text {nd }}$ conjugation ISF tokens was $15 \%$ in Rūta and $14 \%$ in the input.

Verbs belonging to the $3^{\text {rd }}$ conjugation were not shifted, though. Thus, one may conclude that the relevant factor inducing the shifts was the formal similarity of the $1^{\text {st }}$ and $2^{\text {nd }}$ conjugations.

An additional trigger could be the fact that $2 \mathrm{sg}$ and $3^{\text {rd }}$ person forms in the $2^{\text {nd }}$ conjugation have the same endings. The child might have wanted to disambiguate these forms. However, Rūta shifted not only the lemmas in which $2 \mathrm{sg}$ and $3^{\text {rd }}$ person are homophonous, but also those in which these categories are differentiated by stress.

Interestingly, in the data studied one can find very few instances of overregularisations involving morphohonemic alternation in primary verbs (all of them after the age of two).

\section{Concluding remarks}

When analysing the emergence of verb inflection in Lithuanian and comparing it with the development of inflection in other languages, one has to bear in mind that the acquisition of Lithuanian has not been thoroughly studied, and the present contribution is based on the data of one child only. Therefore, one should avoid drawing far-reaching conclusions. One should also take into concern the fact that particular portions of the Lithuanian data differ in their amount which might influence obtained results.

7.1. At 1;7 Rūta used very few lexical items. No derivational processes were involved in verb production and the only morphological categories were the Present tense and the Imperative.

1.3 See Wójcik and Smoczyńska, 1997, Wójcik in press. 
Only one two-member mini-paradigm was recorded. In the following month the situation was similar, however the first $2^{\text {nd }}$ conjugation verbs emerged and the process of early pattern selection could be observed: the child shifted the $2^{\text {nd }}$ conjugation verbs to the $1^{\text {st }}$ conjugation, which was a strongly dominant class in the input during the whole period in question.

The age of 1;9 should be considered a point of transition from premorphology to protomorphology. At this time Rūta's active vocabulary expanded and the first prefixed verbs were recorded. Past and Present tense emerged and the first two-member mini-paradigms were found. The ratio of utterances containing a verb form was still very small.

At $1 ; 10$ the girl was at protomorphological stage. The relative frequency of utterances with verbs increased significantly. A very large number of two-member, as well as the first threemember and larger mini-paradigms were recorded.

7.2. Lithuanian is a highly inflected language, therefore one could expect Ruta to become aware of the role of morphology and to apply it earlier than children speaking languages with little morphological marking. This held true for the data studied. By the end of $1 ; 10$ almost all categories of the Indicative were represented in Rüta's speech. Not all of them, however, were productively and spontaneously used.

As far as the order of acquisition of categories is concerned, one could observe a general tendency in the emergence of unmarked categories before marked ones. The first tense to emerge was the Present tense. Past and Future forms were used by the girl two months later, and periphrastic constructions with participles (so-called 'compound tenses') did not emerge by the age of 2;6. As for the marked moods, the Imperative was frequent in the very first portions of the data, and conditionals were productively used only after the age of two.

Person distinctions emerged before tense distinctions. $3^{\text {rd }}$ person and $1 \mathrm{sg}$ forms were recorded already at 1;7. $2 \mathrm{sg}$ forms were used relatively early as well, however, till the end of the second year of life most of them were non-reversal errors occurring in answers to yes/no questions.

The first form of plural emerged already at $1 ; 8$ and in the following months the number of plurals gradually increased. It has to be marked, however, that during the period under investigation they were used only in modal (mainly hortative) or modelled utterances.

\section{References}

Dressler, Wolfgang U. (1995): Inflectional morphology: Grammar - theoretical preliminaries. Paper presented at the first workshop on Pre- and Protomorphology in Language Acquisition, Vienna, February, 1995.

Ambrazas, Vytautas et al. (eds) (1997): Lithuanian Grammar. Vilnius: Baltos lankos.

Paulauskienè, Aldona (1979): Gramatinès lietuvių kalbos veiksmažodžio kategorijos. Vilnius: Mokslas.

Rüķe-Draviṇa, Velta (1982): No pieciem mēnešiem līdz pieciem gadiem. Stokholm: The Baltic Scientific Institute in Scandinavia.

Wójcik, Paweł (1994): Some characteristic features of Lithuanian Baby Talk. Linguistica Baltica, 3, 71-86.

- (1998): The Acquisition of the Category of Person in the Verb by a Lithuanian Child. Linguistica Baltica, 7.

- (in press): The Acquisition of Lithuanian Verb Morphology. A Case Study.

- / Magdalena Smoczyńska (1997): Acquisition of Lithuanian verb morphology: a Preliminary report, in: Dressler, W.U. (ed.). Studies in Pre- and Protomorphology, Vienna, 83-100. 


\section{Appendix}

Table A1. Inflection of the Lithuanian verb ${ }^{14}$

PRESENT

(inflection based on the Present stem)

\begin{tabular}{|c|c|c|c|c|c|c|c|c|}
\hline & \multirow{2}{*}{\multicolumn{2}{|c|}{$\frac{1 .}{\text { supti }}$}} & \multicolumn{4}{|c|}{2.} & \multirow{2}{*}{\multicolumn{2}{|c|}{$\frac{3 .}{\text { daryti }}$}} \\
\hline & & & \multicolumn{2}{|c|}{ turèti } & \multicolumn{2}{|r|}{ mylèti } & & \\
\hline & singular & plural & singular & plural & singular & plural & singular & plural \\
\hline $\begin{array}{l}\text { 1. person } \\
\text { 2. person } \\
\text { 3. person }\end{array}$ & $\begin{array}{l}\text { sup-u } \\
\text { sup-i }\end{array}$ & $\begin{array}{l}\text { sup+a-m(e) } \\
\text { sup+a-t(e) } \\
\text { sup+a }\end{array}$ & $\begin{array}{l}\text { tur-iu } \\
\text { tur-i }\end{array}$ & $\begin{array}{l}\text { tur }+\mathrm{i}-\mathrm{m}(\mathrm{e}) \\
\text { tur }+\mathrm{i}-\mathrm{t}(\mathrm{e}) \\
\mathrm{dr}+\mathrm{i}\end{array}$ & $\begin{array}{l}\text { myl-iu } \\
\text { myl-i }\end{array}$ & $\begin{array}{l}\text { myl+i-m(e) } \\
\text { myl+i-t(e) } \\
\text { myl+i }\end{array}$ & $\begin{array}{l}\text { dar+a-u } \\
\text { dar+a-i }\end{array}$ & $\begin{array}{l}\mathrm{dar}+0-\mathrm{m}(\mathrm{e}) \\
\mathrm{dar}+\mathrm{o}-\mathrm{t}(\mathrm{e}) \\
\mathrm{r}+\mathrm{o}\end{array}$ \\
\hline
\end{tabular}

PAST

(inflection based on the Past stem)

\begin{tabular}{|c|c|c|c|c|}
\hline & \multicolumn{2}{|c|}{ A. } & \multicolumn{2}{|c|}{ B. } \\
\hline & \multicolumn{2}{|c|}{ supti } & \multicolumn{2}{|c|}{ daryti } \\
\hline & singular & plural & singular & plural \\
\hline $\begin{array}{l}\text { 1. person } \\
\text { 2. person } \\
\text { 3. person }\end{array}$ & $\begin{array}{l}\text { sup+a-u } \\
\text { sup+a-i }\end{array}$ & $\begin{array}{l}\text { sup+o-m(e) } \\
\text { sup+o-t(e) } \\
+0\end{array}$ & $\begin{array}{l}\text { dar+ia-u } \\
\text { dar+e-i }\end{array}$ & $-m(e)$ \\
\hline
\end{tabular}

IMPERATIVE

(inflection based on the Infinitive stem: marker $-k(i)-$ )

\begin{tabular}{|c|c|c|c|c|}
\hline & \multicolumn{2}{|c|}{ supti } & \multicolumn{2}{|c|}{ daryti } \\
\hline & singular & plural & singular & plural \\
\hline $\begin{array}{l}\text { 1. person } \\
\text { 2. person }\end{array}$ & sup-k & $\begin{array}{l}\text { sup-ki-m(e) } \\
\text { sup-ki-l(c) }\end{array}$ & dary-k & $\begin{array}{l}\text { dary-ki-m(e) } \\
\text { dary-ki-l(e) }\end{array}$ \\
\hline
\end{tabular}

FUTURE

(inflection based on the Infinitive stem: marker $-s(i)$-)

\begin{tabular}{|l|lc|lc|}
\cline { 2 - 5 } \multicolumn{1}{c|}{} & \multicolumn{2}{c|}{ supti } & \multicolumn{2}{c|}{ daryti } \\
\cline { 2 - 5 } \multicolumn{1}{c|}{} & \multicolumn{1}{c|}{ singular } & \multicolumn{1}{c|}{ plural } & plural \\
\hline 1. person & sup-s-iu & sup-si-m(e) & dary-s-iu & dary-si-m(e) \\
2. person & sup-s-i & sup-si-t(e) & dary-s-i & dary-si-t(e) \\
3. person & & sup-s & & dary-s \\
\hline
\end{tabular}

${ }^{14}$ Only the categories which will be discussed in the paper are shown. 
Table A2. The distribution of verb forms in Rūta's utterances

\begin{tabular}{|c|c|c|c|c|c|c|c|c|c|c|c|c|}
\hline & $1 ; 7$ & $1 ; 8$ & $1 ; 9$ & $1 ; 10$ & $1 ; 11$ & $2 ; 0$ & $2 ; 1$ & $2 ; 2$ & $2 ; 3$ & $2 ; 4$ & $2 ; 5$ & TOTAL \\
\hline \multicolumn{13}{|c|}{ PRESENT } \\
\hline 1SG & 7 & 9 & 40 & 98 & 58 & 88 & 87 & 111 & 145 & 89 & 102 & 834 \\
\hline 2 SG & & 3 & 16 & 22 & 4. & 1 & 25 & 56 & 21 & 81 & 58 & 287 \\
\hline 3 & 21 & 69 & 169 & 286 & 348 & 337 & 363 & 438 & 373 & 325 & 277 & 3006 \\
\hline 1PL & & 1 & 2 & 6 & 12 & 8 & 16 & 36 & 39 & 55 & 24 & 199 \\
\hline $2 \mathrm{PL}$ & & & & & & 2 & & & & & & 2 \\
\hline total & 28 & 82 & 227 & 412 & 422 & 436 & 491 & 641 & 578 & 550 & 461 & 4328 \\
\hline \multicolumn{13}{|c|}{ PAST } \\
\hline $1 \mathrm{SG}$ & & & 3 & 15 & 27 & 28 & 45 & 28 & 18 & 55 & 46 & 265 \\
\hline $2 S G$ & & & 3 & 6 & 2 & 2 & 7 & 10 & 11 & 13 & 14 & 68 \\
\hline 3 & & & 30 & 57 & 76 & 72 & 113 & 51 & 84 & 126 & 93 & 702 \\
\hline 1PL & & & & 3. & 9 & 4 & 3 & 16 & 6 & 11 & 16 & 68 \\
\hline 2PL & & & & & & & & & & & 1 & 1 \\
\hline total & 0 & 0 & 36 & 81 & 115 & 106 & 168 & 105 & 119 & 205 & 170 & 1105 \\
\hline \multicolumn{13}{|c|}{ FUTURE } \\
\hline 1SG & & & 2 & 30 & 99 & 68 & 113 & 97 & 80 & 106 & 54 & 649 \\
\hline $2 \mathrm{SG}$ & & 1 & 3 & 5 & 1 & & 1 & 4 & $3 \mid$ & 4 & 2 & 24 \\
\hline 3 & & & 9 & 101 & 90 & 44 & 91 & 97 & 148 & 75 & 46 & 701 \\
\hline $1 \mathrm{PL}$ & & & & 12 & 17 & 18 & 28 & 28 & 44 & 40 & 11 & 198 \\
\hline 2PL & & & & & & & & & & & & \\
\hline total & 0 & 1 & 14 & 148 & 207 & 130 & 233 & 226 & 275 & 225 & 113 & 1572 \\
\hline \multicolumn{13}{|c|}{ CONDITIONAL } \\
\hline 1SG & & & & & & 1 & & & & & 1 & 2 \\
\hline 2SG & & & & & & & & & & & 1 & 1 \\
\hline 3 & & & & 11 & 1 & 1 & 2 & 13 & 6 & 4 & 7 & 45 \\
\hline 1PL & & & & & & & & 1 & & & & 1 \\
\hline $2 \mathrm{PL}$ & & & & & & & & & & & & \\
\hline total & 0 & 0 & 0 & 11 & 1 & 2 & 2 & 14 & 6 & 4 & 9 & 49 \\
\hline \multicolumn{13}{|c|}{ IMPERATIVE } \\
\hline 2SG & 14 & 28 & 97 & 146 & 103 & 92 & 205 & 176 & 183 & 181 & 177 & 1402 \\
\hline $1 P L$ & & & & 5 & 2 & & & 1 & & & & 8 \\
\hline 2PL & & & & & & & 1 & & & 3 & & 4 \\
\hline total & 14 & 28 & 97 & 151 & 105 & 92 & 206 & 177 & 183 & 184 & 177 & 1414 \\
\hline \multicolumn{13}{|c|}{ INFINITIVE } \\
\hline total & & 8 & 37 & 75 & 33 & 57 & 98 & 137 & 129 & 99 & 88 & 761 \\
\hline \multicolumn{13}{|c|}{ PARTICIPLES } \\
\hline total & & & 2 & 19 & 40 & 30 & 34 & 11 & 17 & 9 & 19 & 181 \\
\hline \multicolumn{13}{|c|}{ 'galima' } \\
\hline total & & & 3 & & 2 & 18 & 59 & 44 & 65 & 27 & 37 & 255 \\
\hline TOKEN & 42 & 119 & 416 & 897 & 924 & 871 & 1291 & 1355 & 1372 & 1303 & 1074 & 9664 \\
\hline
\end{tabular}


